\title{
Shunt Hybrid Power Filter for Harmonic Reduction to Improve Power Quality using PI and Hysteresis Controller
}

\author{
Saduf Shabeer \\ Department of Electrical \& \\ Electronics engineering \\ Faculty of engineering \& \\ Technology \\ Manav Rachna International \\ University,Faridabad
}

\author{
Ashish Grover \\ Department of \\ Electrical \& Electronics \\ engineering \\ Faculty of engineering \& \\ Technology \\ Manav Rachna International \\ University,Faridabad
}

\author{
Abdul Hamid Bhat, PhD \\ Department of Electrical \\ Engineering \\ National Institute of \\ Technology \\ Srinagar
}

\begin{abstract}
Shunt hybrid power filter are extensively used for current harmonic elimination and to compensate reactive power for linear/nonlinear loads and to improve input power factor. Hybrid power filter is thus used as practical solution to solve the electric power quality (EOQ) issues. Hybrid filter consists of a shunt active power filter (SAPF) and passive filters Shunt active power filter operates at a very low switching frequency, thus giving higher conversion efficiency. The combined operation of shunt active power filter and passive filter ensures total harmonic distortion (THD) of source current should be within the permissible limits set by various regulatory agencies ie $\mathrm{THD}=<5 \%$ and supply power factor is near unity. The effectiveness of the hybrid filter has been verified by the extensive simulation results carried out in MATLAB/Simulink and Sim Power System software.
\end{abstract}

\section{General Terms}

Hybrid power filter, active power filter, hysteresis controller, passive filter, power quality.

\section{Keywords}

THD (total harmonic distortion), PI(proportional integral) controller ,EPQ(electrical power quality) APLC(active power load conditioner),SAPF (shunt active power filter),APF(active power filter)

\section{INTRODUCTION}

Power quality improvement has become a chief research focus in modern power distribution system .In recent years, there has been an tremendous use of power electronics equipments due to low cost and new technologies causing an increased interest for research and development in this area[2][3]. These devices demand high quality energy to work in faultless conditions and performance. Power electronic devices act as a non-linear load and hence result in current rich in harmonics (THD >5\%). Harmonic currents in the power system can distort the line voltage at the point of common coupling (PCC), as a result, leading to a number of undesirable effects such as equipment overheating, malfunctioning of sensitive equipments, improper functioning of relays and interference with communication systems, capacitor failure due to overloading, harmonic resonance. These problems can be solved to a great extent by using power filters at the point of common coupling where the problem has occurred.[3] . In this paper, a simple control design for hybrid filter is developed for compensating the harmonics due to non-linear loads.

Voltage and current harmonics have become a severe setback in transmission and distribution systems in recent years due to increased use of switching devices like adjustable speed drives (ASD), arc furnace, controlled and uncontrolled rectifier etc. To solve the current harmonic related problems, passive filters are connected in various circuit configurations in order to give low cost solution. However, passive filter design to eliminate the current harmonics has some disadvantages such as tuning problems as well as series and parallel resonance [4]. To keep away from this resonance between an existing passive filter and the supply impedance, active power filter (APF) topologies have been proposed and worked on in recent years [1]. In order to overcome the preceding disadvantages of the passive filters, several topologies of active power filters (APFs) have been proposed and there exist several active power filter topologies in the literature [3].

Usual parallel voltage source shunt active power filter is extensively used for the improving THD and source power factor. Shunt APF gives suitable performance i.e. purely sinusoidal source current at unity power factor but it has a disadvantage that the inverter operates at a very high switching frequency which results in higher switching power loss and reduced conversion efficiency, Also active power filter topologies require a large $\mathrm{kVA}$ rating for the power stage. As a result of these disadvantages, the initial operational costs of these active power filters are too high and are not apt on high- or medium-voltage situations.

Thus advantages of the simplicity and the cost effectiveness of passive filters along with the higher performance of active power filters can be used in hybrid filter topologies. They are low cost solutions for compensating harmonics as well as in controlling current variations and distortions.

The four important requirements of a hybrid active power filters scheme are:

1. the kind of converter (the plan, the topology of converter, and the power electronic device used);

2. the control technique (evaluation of the control reference signals);

3. the control method used (how the power inverter follows the control reference, usually through the 
pulse width modulation of the switch device trigger signals, that is, the PWM method);

4. The connection of passive filter.

Initial three objectives are similar for both shunt and hybrid active power filters. So, the design according to the application of the control strategy, and the election and implementation of the control technique are key to the active power filter design. The evaluation of the effect of inserting passive filter is presented here.

\section{TYPES OF ACTIVE POWER FILTERS}

\subsection{Shunt active power filter}

The most common APLC (active power load conditioner) arrangement is the shunt or parallel connection. Figure 1 shows the basic design of the shunt active power filter. Diode represents the nonlinear load; IGBT switching device represents the active power filter block. The loads with current harmonics can be compensated by this type of design. A classic example of a current -source nonlinear load is a rectifier with resistive branch in dc side.

The aim of the shunt active power filter is to inject into the system a compensation current, ic, to cancel the harmonic component of the load current, $i_{L}$. The source current $i_{S}$ becomes sinusoidal past the compensation.

The source current waveform due to a nonlinear load, i.e. a three-phase diode rectifier with a highly inductive DC branch, is shown in Figure 2. The shunt active powers filter connection; which injects a compensation current, Figure 2c, in parallel with the load. Figure.2d shows the source current of the system. Before the compensation is equal to the load current, and after compensation it is sinusoidal. In this example, the source voltage is sinusoidal as shown in Figure.2a.Thus with the help of shunt active filter power quality is improved . Shunt active power filter in due course compensates reactive power and also improves the input power factor and maintains THD $<5 \%$ which is set by various regulatory agencies.

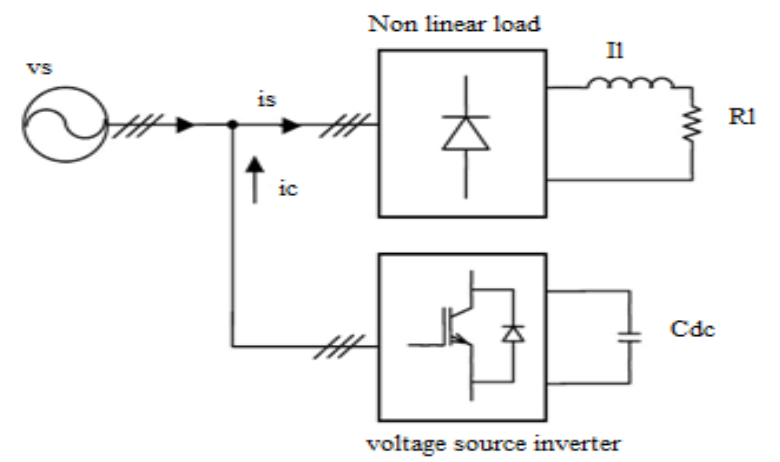

Fig. 1: Shunt Active Power Filter a)

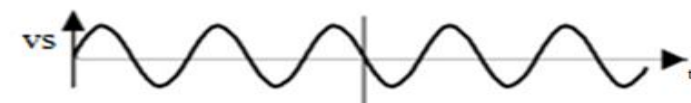

b)

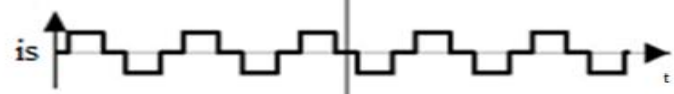

c)

d)

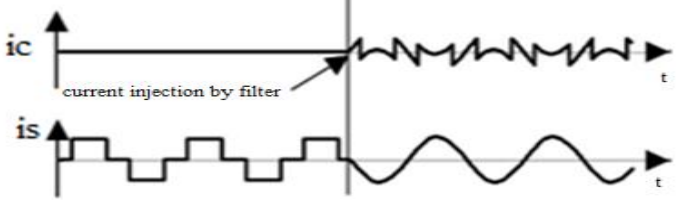

Fig. 2: Shunt Active Filter wave forms

\subsection{Series Active Filter}

Figure 3 shows the connection diagram of a series active power filter. A coupling transformer is used to connect the filter to the system. The compensation voltage, $V_{C}$, is used to cancel the load voltage harmonics caused due to nonlinear load like diode rectifiers with capacitive load in the DC side.

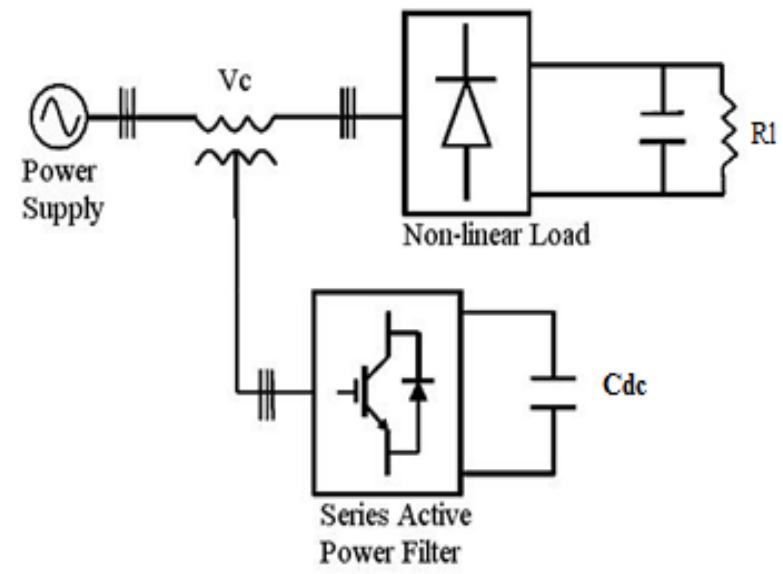

Fig. 3: Series Active Filter

\section{HYBRID POWER FILTER}

Figure 4 shows two types of the hybrid arrangement of passive and active filters. The central endeavor of hybrid combination is to trim down the cost of the static compensation. Main idea of this paper is to operate shunt Active power filter at very low switching frequency to reduced power loss. But this increases the total harmonic distortion. Now the job of passive filter is to do away with the remaining harmonics from source current. The main advantage of this technique is that we obtain sinusoidal source current with unity power factor at reduced switching frequency as compared to shunt APF alone, which achieves the same goals at higher switching frequency. owing to high switching frequency in active power filter which may increase switching loses passive filters are used to cancel the most relevant harmonics of the load, and the active filter is dedicated to improving the performance of passive filters or to cancel other harmonics components. As result, the power of the active filter is reduced, and the passive filter disadvantages (e.g. resonances with the source impedance) are mitigated. In a sketch out, the total cost decreases without reduction of the efficiency. 


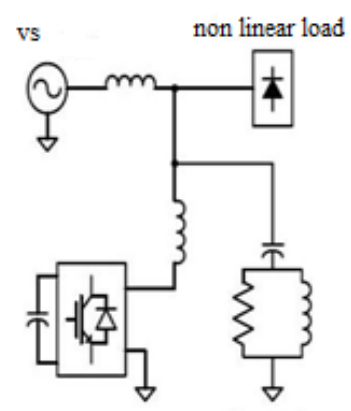

(a) Shunt active power filter

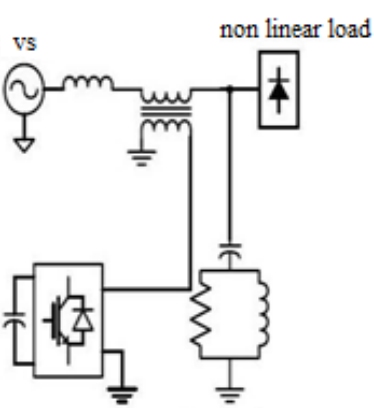

(b) Series active power filter

Fig. 4: Hybrid Active Power Filters

\section{PROPOSED MODELLING OF HYBRID POWER FILTER}

The basic shunt hybrid power filter is shown in figure 4(a). Hybrid power filter thus inserts the advantage of both active and passive filter thus giving advanced and effective result. A diode rectifier with smoothing DC capacitor acts as nonlinear load which creates significant current distortion. The current harmonic amplitude is significantly affected due to AC side or source impedance. Passive Filters have been extensively used in power system to mitigate these harmonic distortions chiefly due to their low cost. In the given paper, current harmonics caused due to the non-linear load, having an R-L load has been taken for analysis as a test system.

SAPF (shunt active power filter) is used to inject the compensating currents in order to have purely sinusoidal source current at unity power factor. It consists of a voltage source inverter (VSI) having a voltage source at the DC bus, which typically is an energy storage device like a capacitor. Figure1 shows the basic compensation principle of a Shunt Active Power Filter in which the compensating current $i_{c}$ cancels the current harmonics on the AC side [1]

From Figure1 the instantaneous source currents can be written as

$$
\mathrm{i}_{\mathrm{S}}(\mathrm{t})=\mathrm{i}_{\mathrm{L}}(\mathrm{t})-\mathrm{i}_{\mathrm{c}}(\mathrm{t})
$$

Source voltage is given by

$$
\mathrm{v}_{\mathrm{s}}(\mathrm{t})=\mathrm{V}_{\mathrm{m}} \sin \omega \mathrm{t}
$$

For a non-linear load, the load current will have a fundamental component and the harmonic component, which can be further given by: $\mathrm{i}_{\mathrm{L}}(\mathrm{t})=\sum_{\mathrm{n}=1}^{\infty} \mathrm{I}_{\mathrm{n}} \sin \left(n \omega t+\phi_{n}\right)=$ $\mathrm{I}_{1} \sin \left(\omega t+\phi_{1}\right)+\sum_{n=2}^{\infty} \mathrm{I}_{\mathrm{n}} \sin \left(\mathrm{n} \omega \mathrm{t}+\phi_{\mathrm{n}}\right)$

Instantaneous load power can be given as:

$$
\begin{aligned}
& \mathrm{p}_{\mathrm{L}}(\mathrm{t})=\mathrm{v}_{\mathrm{s}}(\mathrm{t}) * \mathrm{i}_{\mathrm{L}}(\mathrm{t}) \\
&=\mathrm{V}_{\mathrm{m}} \mathrm{I}_{1} \sin ^{2} \omega \mathrm{t} * \cos \phi_{1}+\mathrm{V}_{\mathrm{m}} \mathrm{I}_{1} \sin \omega \mathrm{t} * \cos \omega \mathrm{t} * \sin \phi_{1} \\
& \quad+\mathrm{V}_{\mathrm{m}} \sin \omega \mathrm{t} * \sum_{\mathrm{n}=2}^{\infty} \mathrm{I}_{\mathrm{n}} \sin \left(\mathrm{n} \omega \mathrm{t}+\phi_{\mathrm{n}}\right)
\end{aligned}
$$

$$
=\mathrm{p}_{\mathrm{f}}(\mathrm{t})+\mathrm{p}_{\mathrm{r}}(\mathrm{t})+\mathrm{p}_{\mathrm{h}}(\mathrm{t})
$$

From (4), real (fundamental) power drawn by the load

$$
\mathrm{p}_{\mathrm{f}}(\mathrm{t})=\mathrm{V}_{\mathrm{m}} \mathrm{I}_{1} \sin ^{2} \omega \mathrm{t} * \cos \phi_{1}=\mathrm{v}_{\mathrm{s}}(\mathrm{t}) *
$$

$\mathrm{i}_{\mathrm{S}}(\mathrm{t})$

From (6) source current supplied by the source after compensation:

$$
\mathrm{i}_{\mathrm{s}}(\mathrm{t})=\frac{\mathrm{p}_{\mathrm{f}}(\mathrm{t})}{\mathrm{v}_{\mathrm{s}}(\mathrm{t})}=\mathrm{I}_{1} \cos \phi_{1} \sin \omega \mathrm{t}=\mathrm{I}_{\mathrm{sm}} \sin \omega \mathrm{t}
$$

Where $\mathrm{I}_{\mathrm{sm}}=\mathrm{I}_{1} \cos \phi_{1}$

Hence total peak current supplied by the source:

$I_{\mathrm{sp}}=\mathrm{I}_{\mathrm{sm}}+\mathrm{I}_{\mathrm{sL}}$

Where, $\mathrm{I}_{\mathrm{SL}}$ represents the PWM converter switching losses.

In case active power filter provides the total reactive and harmonic power, then $i_{s}(t)$ will be in phase with the service voltage and will be entirely sinusoidal. At this point of time, compensation current is:

$$
\mathrm{i}_{\mathrm{c}}(\mathrm{t})=\mathrm{i}_{\mathrm{L}}(\mathrm{t})-\mathrm{i}_{\mathrm{s}}(\mathrm{t})
$$

Thus it is important to compute $i_{s}(t)$ for precise and instantaneous compensation of reactive and harmonic power.

\section{PROPOSED CONTROL STRATEGY}

The control block of hybrid power filter is shown in figure 5 below

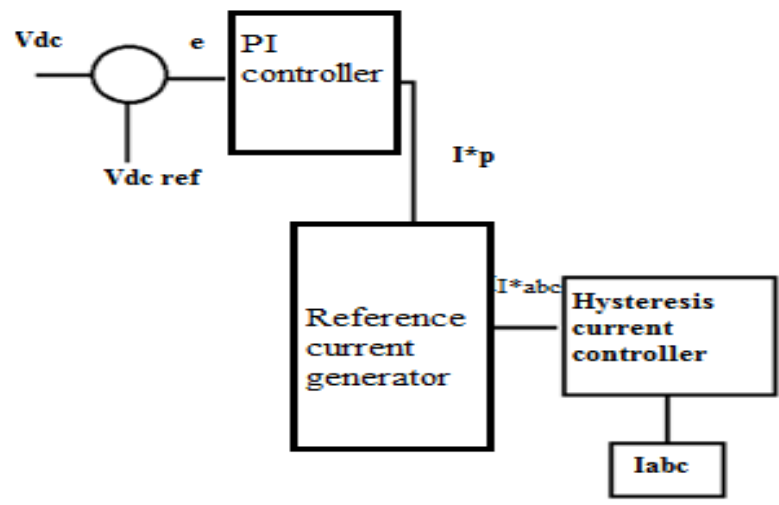

Fig. 5: control block of hybrid power filter

A three-phase shunt active power filter consisting of a voltage source inverter (VSI) having IGBT switches and an energy storage capacitor on DC bus. The control block consists of the PI controller and the Hysteresis current controller (HCC). The work of PI controller is the evaluation of reference current from the measured DC bus voltage. The job of HCC is to generate the switching pulses for the VSI. HCC comprises of the following components:

\subsection{Unit vector template formation.}

The input source voltage at point of common coupling (PCC) consists of fundamental and distorted component. In order to get unit vector templates of voltage, the input voltage is sensed and multiplied by gain which is equal to $1 / \mathrm{vm}$, where $v m$ represents the peak amplitude of fundamental input voltage. These unit vector templates are then given to a multiplication block for synchronization of signals. The unit vector templates for three phases are obtained as follows:

$$
\begin{aligned}
& v s a=\sin \omega t \\
& v s b=\sin \left(\omega t-120^{\circ}\right) \\
& v s c=\sin \left(\omega t+120^{\circ}\right)
\end{aligned}
$$




\subsection{Reference source current evaluation}

The peak value of the reference current Isp can be determined by controlling the DC side capacitor voltage. The best compensation requires the mains current to be sinusoidal and in phase with the source voltage irrespective nature of load current. The desired source current after compensation is given by:

$$
\begin{aligned}
& l_{s a}=\text { Isp } \sin \omega \mathrm{t} \\
& t_{s b}^{*}=\text { Isp } \sin \left(\omega \mathrm{t}-120^{\circ}\right) \\
& i_{s c}^{*}=\mathrm{Isp} \sin \left(\omega \mathrm{t}+120^{\circ}\right)
\end{aligned}
$$

Here Isp (=I1 cos $\phi 1+$ IsL) is the amplitude of the desired source current, while the phase angles can be obtained from the source voltage. Thus, the waveform and phases of the source currents are known, just the magnitude of the source currents needs to be determined.

Peak value of the reference current has been obtained by regulating the dc side capacitor voltage of PWM converter. This capacitor voltage is compared with the reference value and the error is processed in a PI controller. The output of PI controller is the amplitude of the desired source current and the reference currents are estimated by multiplying this peak value with the unit sine vector templates in phase with the source voltages.

\subsection{Control strategy used in HCC}

Hysteresis Current Control (HCC) technique is basically an instantaneous feedback current control method of pulse width modulation (PWM) where the actual current continually tracks the command current within a hysteresis band. The actual source currents isa, isb and isc are compared in hysteresis current controller in order to generate the control pulses for switches of VSI in such a way so that the actual source current follows the reference currents closely inside the narrow hysteresis band. This makes source currents almost sinusoidal and in phase with source voltages, thus giving unity power factor.Figure.6 shows the basic principle of HCC technique

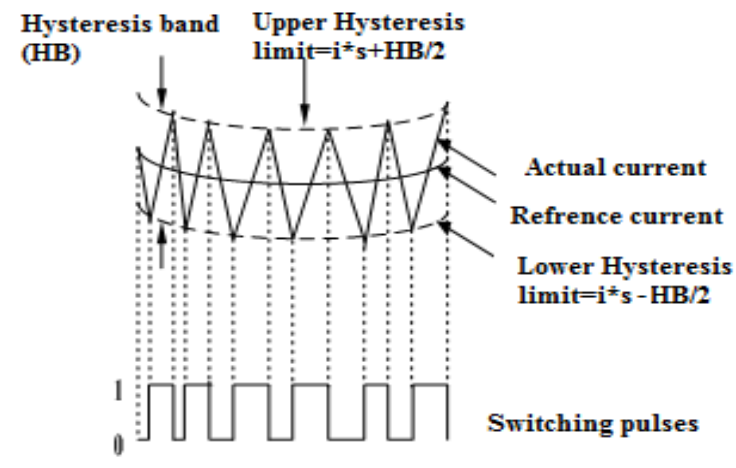

Fig.6: Hysteresis Current Control Technique

Hysteresis band (HB) is the potential boundary of the compensating current. This current deviates between upper and lower hysteresis limits. For example in phase $a$, if is $a$ is equal or over than the upper hysteresis limit (isa* $+\mathrm{HB} / 2)$ then the comparator output is $0(\mathrm{~S} 1=0, \mathrm{~S} 2=1)$. As a result, current starts to decay [5]. On the other hand, if is $a$ is equal or less than the lower hysteresis limit $\left(i s a^{*}-\mathrm{HB} / 2\right)$ then the comparator output is $1(\mathrm{~S} 1=1, \mathrm{~S} 2=0)$. As a result current gets back into the hysteresis band. From this operation, the is a can deviate inside the hysteresis band following the reference current $i s a^{*}$. The key benefit of hysteresis current control method is its outstanding dynamic response, effortless implementation and economical.

The switching frequency of hysteresis current control approach described above depends mainly on how fast the current changes from upper to lower boundary of hysteresis band and inversely. As a result, the switching frequency does not remain constant all the way through the switching operation but changes along with the current waveform.

Figure 7 represents the basic plan for generation of six pulses so as to drive the six switches of inverter of the shunt active power filter. In this method the actual output current generated by inverter is compared with reference current generated with the help of PI controller and unit sine vectors. Hysteresis current controller will produce pulses in such a way that inverter output current follows the reference current.

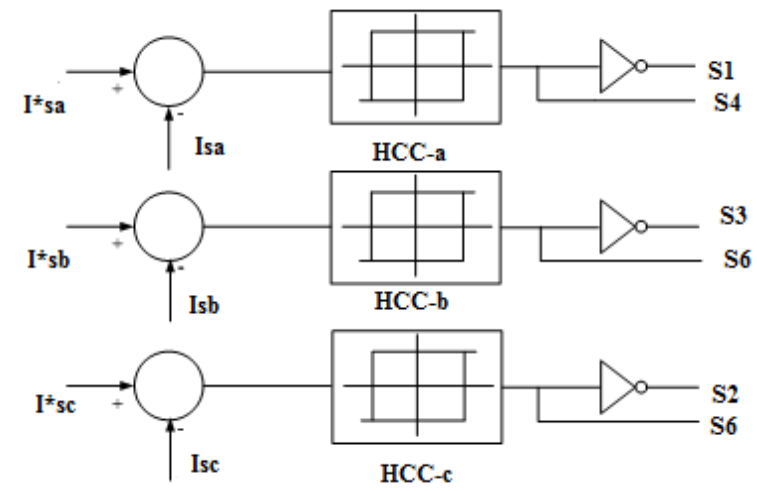

Fig. 7: Pulse Generation Using Hysteresis Current Control Technique

\subsection{Passive filter design and its filtering characteristics}

Basic idea of this paper to operate shunt Active power filter at very low switching frequency in order to reduced power loss and to add advantages of both passive and active filter for superior performance. But operation at low switching frequency may increase harmonic distortion, now the role of passive filter is to remove the remaining harmonics from source current to improve THD. The main benefit of this technique is that we attain sinusoidal source current with unity power factor at reduced switching frequency as compared to shunt APF alone, which achieves the same objectives at higher switching frequency.

The hysteresis band chosen is large for lower switching frequency and hence higher conversion efficiency and vice versa for high switching frequency. The increased current harmonics caused due to large hysteresis band in case of hybrid power filter is removed efficiently by a high pass filter (Passive filter), thus resulting is reduced source current THD at higher efficiency.

\subsection{PI Controller}

The work of PI controller is the evaluation of reference current from the measured DC bus voltage. Proportional Integral (PI) controller has been extensively used for DC bus voltage regulation in shunt active power filters. It is effortless to implement and achieves excellent results. The control scheme of a shunt active power filter should calculate the 
reference current waveform for each of the three phase of the inverter, maintain the dc link voltage constant, and generate the inverter gating pulses.

PI controller consists of a proportional term i.e. Kp and an integral term i.e. Ki. Proportional value is used determines the response to the current error; similarly the Integral part is used to determine the response based on the sum of recent errors. The transfer function of the PI controller is given by:

$$
\mathrm{H}(\mathrm{s})=\mathrm{K}_{\mathrm{P}}+\frac{\mathrm{K}_{\mathrm{I}}}{\mathrm{s}}
$$

Here, the proportional and integral gains are selected either heuristically or mathematically. The integral term causes the steady-state error to trim down to zero; however it is not the case for proportional-only control. PI controllers are commonly used than Proportional Integral Derivative (PID) controllers because the derivative action is very sensitive to noise, in this manner making PI system steadier in the steadystate in the case of a noisy environment.

\section{SIMULATION RESULTS}

The proposed system is simulated using MATLAB/Simulink and Sim Power Systems software to validate the performance of proposed method. The system parameters are presented in Table-I.

Table 1: Simulation Parameters And Specifications

\begin{tabular}{|c|c|c|}
\hline S.NO. & PARAMETERS & Value \\
\hline 1. & Source Voltage & $230 \mathrm{~V}(\mathrm{r} . \mathrm{m} . \mathrm{s})$ \\
\hline 2. & Source Frequency & $50 \mathrm{~Hz}$ \\
\hline 3. & DC bus voltage & $600 \mathrm{~V}$ \\
\hline 4. & DC bus capacitor & $2400 \mu \mathrm{F}$ \\
\hline 5. & DC link inductance & $1.5 \mathrm{mH}$ \\
\hline 6. & Hysteresis Band & \pm 5 \\
\hline 7. & Load resistance & $8 \Omega$ \\
\hline 8. & Load inductance & $20 \mathrm{mH}$ \\
\hline
\end{tabular}

The system is first simulated without filter in order to investigate the effect of non- linear loads in power systems. Figure 8 shows the phase 'a' source current drawn by nonlinear load in absence of hybrid power filter. The result shows that the current drawn is not sinusoidal and is not in phase with the source voltage.

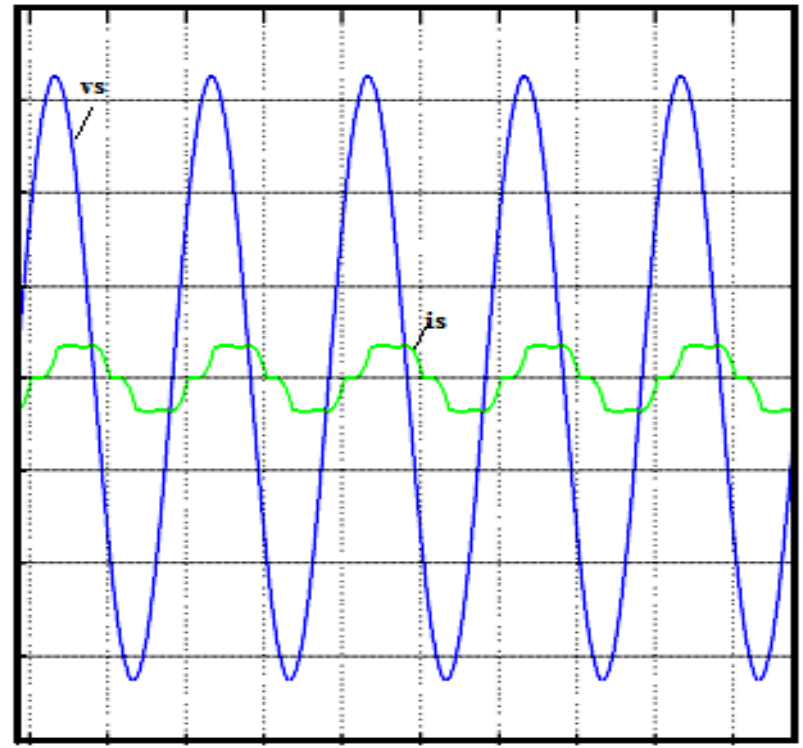

Fig.8: source current without hybrid power filter

When filter is not used THD is also high due to nonlinear load. Figure 9 shows THD due to nonlinear load in absence of filter.

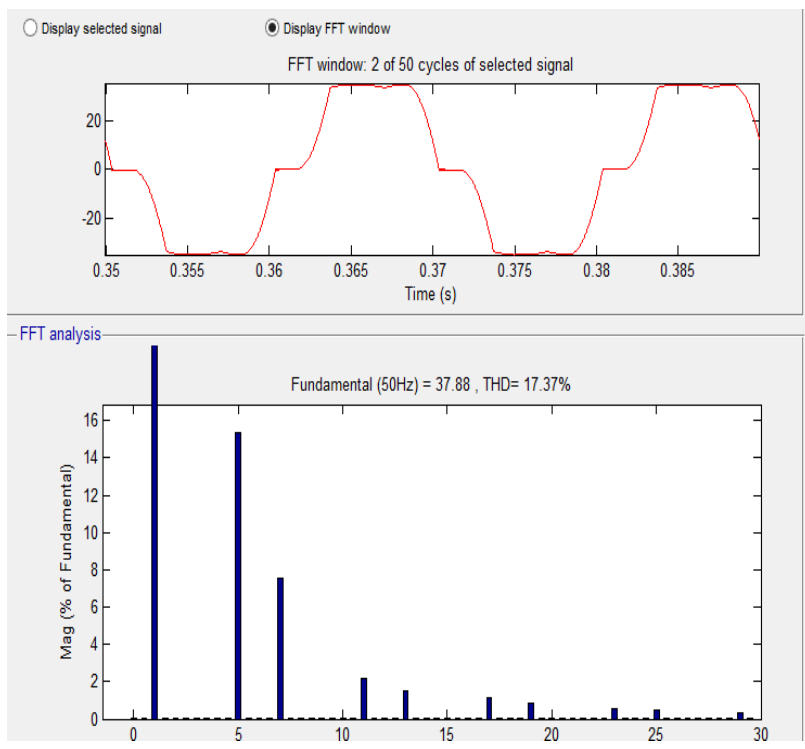

Fig.9: THD due to non linear load in absence of filter (harmonic spectrum)

The source current is highly distorted with a THD of $17.37 \%$ as shown in Figure 9. The source current THD is much greater than the acceptable limit of 5\% set by IEEE-519-1992 standard.

Now a hybrid filter (combination of shunt APF and passive filter) is used for harmonics and reactive power compensation. Figure 10 shows the source current has become near sinusoidal after using hybrid power filter thus improving the power factor and reducing THD from 17.37 to 2.90 as shown in fig. 11 


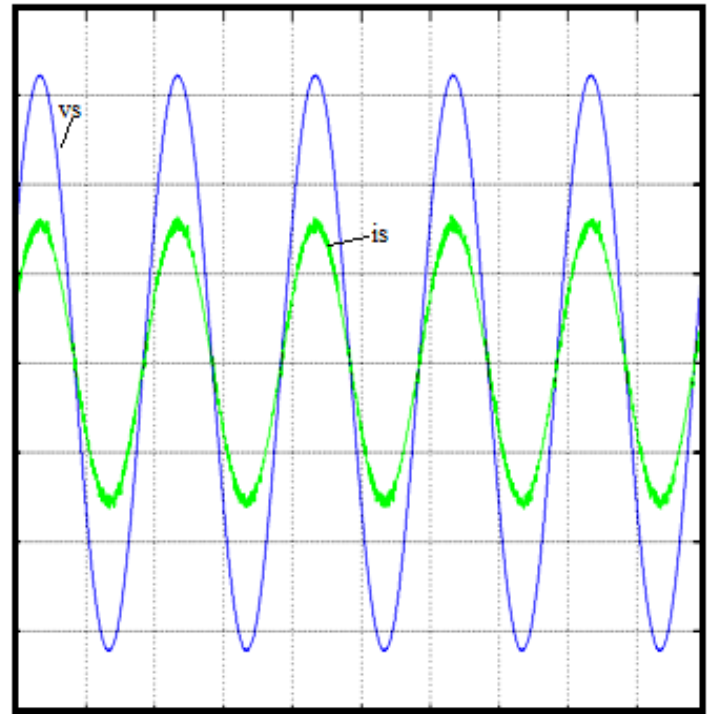

Fig.10: source current with hybrid filter

As a result, the hybrid filter gives nearly harmonic free source current.

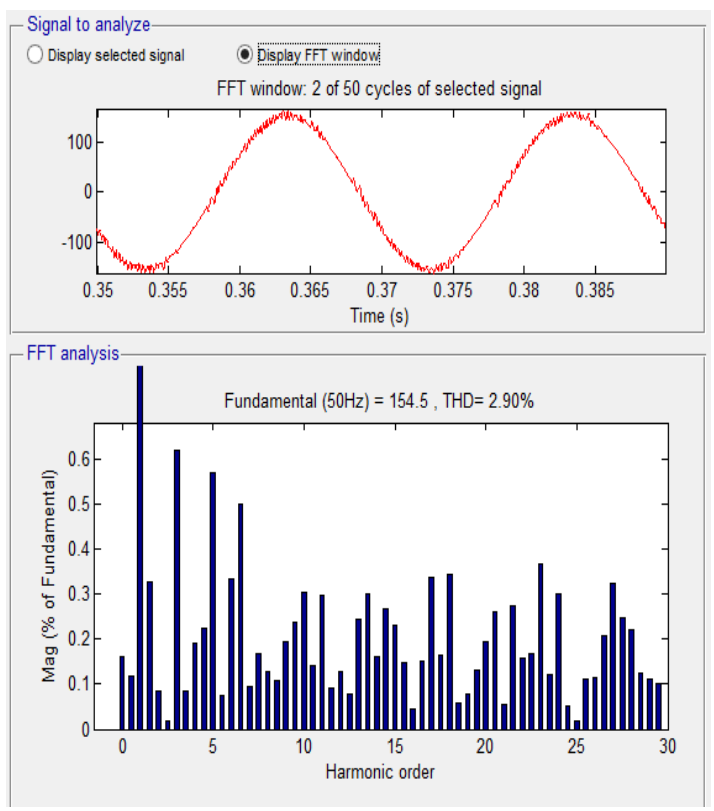

Fig .11 THD due to hybrid power filter (harmonic spectrum)

Table 2 shows the comparative analysis of Shunt Hybrid Filter to reduce the THD.

Table 2: simulation result

\begin{tabular}{|c|c|}
\hline Filter & THD \\
\hline $\begin{array}{c}\text { Without Shunt Hybrid Power } \\
\text { Filter }\end{array}$ & 17.37 \\
\hline $\begin{array}{c}\text { With Shunt Hybrid Power } \\
\text { Filter }\end{array}$ & 2.90 \\
\hline
\end{tabular}

\section{CONCLUSION}

A broad performance evaluation of hybrid power filter using PI controller for power quality improvement has been presented in this paper. The PI based hybrid filter results in close to sinusoidal source current and close to unity input power factor and reduction of total harmonic distortion in accordance with IEEE standard 519(i.e. THD within 5\%).; the proposed technique is found extremely satisfactory to stabilize dc link voltage.

Hybrid filters topologies help in damping resonances occurring between line impedances and passive filters and provide cost-effective, superior efficiency, improved reliability and better solutions for harmonic compensation with an extremely small-rated inverter as compared to active

power filter topologies and other options of power quality improvement. Thus it could be an economical solution to deal with current harmonics issues. Moreover, this design requires compact size of shunt active power filter.

The work done can be further extended by simulating proposed control strategy with grid fault condition and study the performance of filter under fault condition. Different type of controller like fuzzy logic controller, neural and other artificial intelligence controller (AI) can be used in order to obtain better result.

\section{REFERENCES}

[1] Farooq, A. and Bhat, A.H., (2015)," Performance Evaluation of a Three phase Shunt Active Power Filter For power Quality Improvement."

[2] Report by Deepak C.Bhonsle. "Design and implementation of single phase shunt active power filter for harmonic mitigation in distribution system" The M.S.University of Baroda.

[3] H. Akagi, "Active harmonic filters," Proc. IEEE, vol. 93 , no.12,pp.2128-2141,Dec.2005

[4] Jacobs J,Detjen" D,-A new hybrid filter versus a shunt power filter", in European conference on pwer electronics \&applications, Graz,Ausreia 2001.

[5] Prof.dr.Dobariya,Prof.P.Upadhyay,(2015),"'Simulation and comparison between hybrid active power filter and shunt active power filter."

[6] Engin Ozdemir, Mehmet Uca,r Metin Kesler, Murat Kale." The Design and Implementation of a Shunt Active Power Filter based on Source Current Measurement " 1 4244-0743-5/07/\$20.00 @2007 IEEE pp. 608 to 613

[7] Moleykutty George and Kartik Prasad Basu, "Modeling and Control of Three Phase Shunt Active Power Filter," in American Journal of Applied Sciences 5 (8): 10641070, 2008.

[8] S. J. Huang, J. C. Wu and D. D. Divan, "A control algorithm for three phase three-wired active power filters under nonideal mains voltages,' IEEE Transactions on Power Electronics, vol. 14, pp. 753---760, July 1999.

[9] M.Sarra,K.Djazia,A.Chaoui,F.Krim,“Three-phase Active Power filter with Proportional Integral control," Journal of Electrical Systems Issue no.1,pp 7984,Nov.2009.

[10] Asiminoaei, L. F. S. Blaabjerg, Hansen. -Evaluation of harmonic detection methods for active power filter applications\|, APEC2 5, Vol.1 pp 635-641 